An exploratory study of British Millennials' attitudes to the use of live animals in events

Elena Marinova,

Department of Events \& Leisure, Bournemouth University, Poole, England

Dorothy Fox, (corresponding author)

Department of Events \& Leisure, Bournemouth University, Poole, England

dfox@bournemouth.ac.uk 


\title{
An exploratory study of British Millennials' attitudes to the use of live animals in events
}

\begin{abstract}
Ethical issues related to animal rights have gained significant exposure in the past few decades. As a result, animal welfare concerns have continuously been at the forefront of public debate. This has had a major impact on Western culture, expressed in the growing popularity of lifestyle changes towards reducing and abandonment of animal use across different industries. However, animal use in planned events remains insufficiently studied and absent from most event management literature. Therefore, this research aims to explore the opinions of Millennials on the use of live animals in events. The literature discusses anthropocentrism, anthropomorphism and cognitive dissonance, as reoccurring themes. A combination of a focus group and semi-structured interviews was undertaken and the analysis identified entertainment, financial benefit and tradition as the main reasons for using live animals at events. Awareness and transparency on animal welfare issues within the events industry were stated by interviewees as points for improvement together with the lack of a clear definition of animal welfare, especially when it comes to captive and performing animals, as well as the uncertainty regarding animals' stakeholder status in events.
\end{abstract}

Key Words: events; animal welfare; anthropomorphism; performing animals; animal rights; animals as stakeholders.

Word count: 7,746 


\section{Introduction}

Events are unique representations of culture and tradition and as such they express and form people’s attitudes and beliefs (Hall, 1997) and have the power to directly affect opinions and inspire change (Getz, 2005). Therefore, event organisers carry a certain amount of responsibility to reinforce positive social practices and behaviours and avoid those that are unethical and immoral (Bowdin, Allen, O’Toole, Harris \& McDonnell, 2011). Wilson (1984), suggests that people's psychological health is associated with their relationship to nature, a phenomenon called biophilia. Studies have confirmed this theory, showing that interactions with animals and feeling in harmony with nature offer health and well-being benefits to humans (Penn, 2003). This intrinsic desire to connect with the natural world can serve as an explanation for humanity's fascination with animals. Up until the early 1900s the attitude towards animals was largely characterised by anthropocentrism, or the perceived superiority and exceptionalism of humans compared to the rest of the natural world (Garner, 1993). This view has been changing and evolving throughout the twentieth century and culminated in animal rights \& welfare becoming a pivotal discussion in recent years. This shift in morals translates to lifestyle changes, such as identifying as a vegetarian/vegan and minimising one's consumption of products or services that include the use of animals. The number of people adopting a vegan lifestyle 'has doubled twice in the last 4 years' (The Vegan Society, 2018). This growth is believed to be a consequence of more information being publicly available about how animals are treated across different industries (Moss, 2016).

Both in theory and practice, stakeholder analysis plays a pivotal role in event management (Shone \& Parry, 2010). Traditionally, a stakeholder is defined as any individual or 
organisation that has an interest in, or is influenced by, an organisation or project (Donaldson \& Preston, 1995). Thus, anyone involved in the production, delivery and experience of an event is considered a stakeholder (Allen, O’Toole, Harris, \& McDonnell, 2011). Therefore, it can be argued that when animals are involved in an event, they should be assigned a stakeholder status. Allen et al. (2011) state that an event's impact can be determined by looking at how effectively the needs of different stakeholders are met. This leads to the need to observe how, if at all, an animal's needs are identified and considered. One might argue therein lies the purpose of animal welfare legislation. However, the issue is that a universal definition of animal welfare does not exist (Haynes, 2008). According to Jasper \& Nelkin (1992) animal welfare is not expressed in abandonment of using animals, but rather in ensuring less suffering is caused to them where they are used. An opposing perspective is 'animal liberation' - the belief that animals are entitled to moral consideration equal to that of humans, and capitalising on them should be discontinued (Haynes, 2008). 2). Dashper (2016, p. 23) argues the relationships between people and animals cross 'species, spatial, sensory and temporal boundaries' and goes on to explain these issues 'are complex and highly debated and no consensus has been reached amongst academics and practitioners'.

Getz (2012) states event research requires a multidisciplinary approach, studying culture, human behaviour, morals and sociology in order to be valuable. Furthermore, Jones (2014) states creating a lasting and sustainable event legacy is at the centre of producing events that nurture positive changes in society. Some aspects of ensuring sustainability, however, are less tangible and harder to measure, such as the effect on culture, communal thinking and consumer behaviour. Getz (2012, p. 91) argues people 'cannot be ethical or moral in isolation', thus, highlighting the impact one's social environment has on their moral 
philosophy. Getz proceeds to explore whether ethics is determined by law, or if morality brings an additional set of rules, beyond what is regulated by governing bodies. Despite this recognition of the importance for event management practices to be both sustainable and ethical, event theory discussing the ethics of animal use in planned events is limited. Many countries, including the United Kingdom, have introduced bans on performing animals in circuses, for example, yet other ways in which animals are involved in events remain permitted and widely unexplored. Considering the different beliefs about animal rights, this study aims to explore and understand Millennials' thoughts and feelings on using live animals in planned events. Millennials in the UK have been defined by Parliament as 'Roughly aged between 25 and 34' (Brown et al. 2017, p. 3) and they make up 13.9\% of the total UK population. To achieve this the following objectives were developed:

1. To explore philosophies held by Millennials in relation to the natural world and animals in particular

2. To discuss the reasons for animal use in planned events according to Millennials

3. To observe participant's perceptions of animal treatment in the events industry

4. To encourage participants to identify areas for improvement and ways to act on animal welfare issues at events.

\section{Literature Review}

\section{Nature-related philosophies}

Debates on animal welfare date back to Antiquity. Ancient Greece offers varied opinions on the matter, the philosopher Pythagoras being the first known animal rights advocate. Pythagoras subscribed to animism - the belief that all components of the natural world 
(plants, humans, animals, land, etc.) are connected by a common spirit (Stringer, 1999). A similar philosophy is ecocentrism which assigns value to all living things and their habitats, unrelated to their usefulness to humanity (Gautam \& Rajan, 2014). In contrast, another Ancient Greek philosopher, Aristotle, argued that human beings and animals share the same material features, but are distinguished by the mind (Adler, 1997). Aristotle believed only humans can think abstractly and demonstrate intelligence and thus, considered animals inferior to humanity (Adler, 1997). Later, during the French Renaissance, Montaigne argues animals are no less mentally capable than humans (Kenny, 2012), describing the complex behaviour of animals in support of his views. However, another French philosopher, Descartes, saw animals as mechanical beings, void of thought and feelings. This view is one of the components of anthropocentrism, which has filtered through history and is still adopted by many today (Steiner, 2005). Anthropocentrism is demonstrated by viewing humans as superior to other beings, by supporting the idea that humans exist separate from, and are not existentially connected to the rest of nature, and also by seeing the environment as a resource to be exploited ( $\mathrm{Zu} \&$ Fox, 2014).

Conversely, a philosophy which serves as a basis for much of today’s arguments in favour of giving animals a moral status is ethical utilitarianism, made popular by the eighteenth century English philosopher Jeremy Bentham. Bentham argues the righteousness of an action depends on whether it achieves the 'greatest happiness of the greatest number' (Bentham, 1789 cited in Schultz 2017 p. 67). Bentham intentionally does not specify what the 'number' refers to, as he argues ethical consideration should be extended to other species based on the object's ability to experience suffering: 
...the question is not, Can they reason? nor, Can they talk? but, Can they suffer? Why should the law refuse its protection to any sensitive being (Bentham, 1789 cited in Rollin 2016, p. 11).

After more than 2500 years, there is still no consensus on what rights animals should be assigned (Ryder, 2000). Most of the work on the issue is written after the 1970s when the animal rights movement saw a dramatic increase in popularity (Adams, 2010). The catalyst for this is believed to be Richard Ryder's and later, Peter Singer's publications on the matter. In 1970 Ryder (1970) coined the term speciesism - putting one’s own species’ interests above those of other species - intentionally establishing a link with sexism and racism. Subsequently, Singer supported Ryder's views and argued speciesism is born from unjustified prejudice merely based on biological features, thus, suggesting that animals should be considered morally equal to humans. In their latest collaborative work Ryder \& Singer (2011) put forward the term of painism as a new ethical idea that stands for assigning moral rights to all living beings capable of suffering. Fennell (2012, p. 41) also explores the capacity for suffering as one of the variables that should be considered when debating animals' moral status whilst also discussing moral agency. Moral agency is the ability to assess the ethical implications of one's behaviour, which subsequently makes the agent responsible for the consequences of their actions. While Machan (2002) states human use of animals is justifiable due to animals' assumed lack of moral agency, Shapiro (2006) argues some non-human animals' observed behaviour when relating to other animals, both from their own and different species, serves as proof that non-human species can indeed demonstrate moral agency. Ethological research (the study of animal behaviour) shows animals manifest compassion, cooperation and deep emotions such as love and grief (Fennell, 2012). However, there has been very little research on this and the existing studies have not 
been given significant attention, possibly due to financial and professional interests (Fennell, 2012). Fennell (2012) further challenges human perception of animals' emotional abilities by suggesting that 'not being willing to understand the capacity for animals to feel is perhaps a limitation in the sensory capacity of humans.' (Fennell, 2012, p.43)

Many authors have tried to pinpoint the criteria upon which people judge the moral status and intrinsic value of animals. The factors prevalent in the existing literature are the ability to show empathy and emotion (Singer, 2011; Fennell, 2012), intellectual capabilities, autonomous thinking (Cochrane, 2009) and capacity for suffering (Bentham, 1789 cited in Schultz 2017; Singer, 1990; Fennell, 2012).

\section{Determinants of attitudes to animals}

There are a number of studies (Galvin \& Herzog, 1992; Curtin, 2006: Knight \& Barnett, 2008; Apostol et al., 2012) examining the causes of people adopting a certain view on animals. Gender is one determinant with women often manifesting greater concern for animal welfare issues (Apostol, Rebega \& Miclea, 2012). Another factor is the ability to empathise with them (Galvin \& Herzog, 1992; Apostol et al., 2012). Individuals demonstrating anthropomorphic views see animals as having qualities similar to humans and therefore find it easier to empathise with them. Thus, people with anthropomorphic tendencies approve of animal use less frequently than those who view animals as significantly different to humans (Galvin \& Herzog, 1992). Galvin \& Herzog investigated how a person's moral views affect their attitudes towards animal use through the Ethics Position Questionnaire (EPQ) developed by Forsyth (1980). Comparing animal rights activists to college students, Galvin \& Herzog (1992) found ethical ideology also plays a significant part in how one relates to the natural world. Overall, animal rights activists demonstrate an 'absolutist' moral view of the world, which is characterised by high idealism and the belief ethical principles can be universally applied. The opposite view is relativism, the philosophy that whether an action is ethical or 
not, is to be judged on a case-by-case basis (O’Grady, 2002). As found by Galvin \& Herzog (1992), college students not involved in animal rights campaigning, expressed a more relativist philosophy in relation to animal welfare.

Knight \& Barnett (2008) explored how people's views change depending on the animal's species as well as the purpose of use. Their findings show an individual's views are highly dependent on their experiences of interacting with animals - people were likely to oppose animal use if they considered the animal aesthetically attractive, more mentally and emotionally capable, or had spent time with an animal of the same species. This could be an explanation of people's admiration for some domesticated species in particular, such as dogs or cats, as they are more likely to have experience of them. Similarly, Daly \& Morton (2009) found a correlation between spending time with animals and having anthropomorphic beliefs - a pet owner or someone who grew up with animals, is more likely to perceive them as human-like. Participants in Knight \& Barnett's (2008) study gave the least approval to the use of animals for fashion, cosmetics, entertainment and sport. However, revisiting the overall findings from the same study suggests that the participants' views are influenced not only by the purpose of animal use, but also by one's personal background. For example, some participants disapproved of fox hunting whilst being regularly involved in fishing. Higher levels of education on the topic and first-hand experiences have been linked to lower levels of support for many forms of animal use (Broida, Tingley, Kimball \& Miele, 1993; Pifer, Shimizu \& Pifer, 1994 and Knight \& Barnett 2008). Even though there is a significant lack of knowledge and research on animal ethics, making information available and educating the public does not come without challenges. Knight \& Barnett (2008) found people deliberately avoid upsetting information about animal use, realising such knowledge might prevent them from enjoying elements of their daily life. Behaviour such as this was described as cognitive dissonance by Festinger (1957). 
In a study by Curtin (2006) similar findings are demonstrated after investigating people’s experiences of swimming with dolphins and the changes in their view of the species because of the encounters. The research involved interviewing people who swam with captive dolphins (SCD) in a controlled environment, and others who had an encounter with the animals in the wild (SWD). She found that witnessing animals in their natural habitat is more satisfying to humans than having watched captive animals. Comparing SWD respondents to the SCD group reveals participants' different views on the way humans relate to nature. SWD participants appear less anthropocentric, considering captivity unethical. The SCD group express similar concerns, but they attempt to justify it by focusing on the animals' emotional connection with their trainers and the care dolphins receive. In other words, SCD interviewees demonstrated cognitive dissonance expressed in their avoidance of information that can add to the uncomfortable feelings associated with contributing to captivity (Festinger, 1957). Curtin concludes that the dissonance resulting from encounters with captive dolphins is a result of the participants' anthropomorphic image of dolphins, expressed in the perception animals derive comfort from their relationship with their trainers. Her analysis creates a different perspective on anthropomorphism, directly opposing the findings discussed earlier, where anthropomorphism was found to have a positive effect on reducing animal use due to feelings of empathy (Galvin \& Herzog, 1992).

\section{Animals in culture, tradition \& events}

Leventi-Perez (2011) argues human perception of animals is shaped by external factors - the anthropomorphic representation of animals in Disney films, for example, which is characterised by attributing human qualities and behaviours to unhuman beings, e.g. animals \& plants (Serpell, 1996). Anthropomorphic images are arguably ingrained in the human mind 
as a result of animal portrayal in popular media. This phenomenon, discussed by De Waal (2001, p.71), is described as ‘bambification’ - stripping wildlife of primal instincts, generally perceived as negative, and building an animal's image around 'cuteness' and other more marketable qualities. Arguably, as observed earlier from Curtin’s (2006) and Knight \& Barnett's (2008) studies, such representation of animals is double-edged - while it might help viewers relate to animals, it does little for the connection between humans and 'real' nature. As a result, people's understanding of true animal behaviour is distorted which leads to further detachment from the natural world (Leventi-Perez, 2011). Fennell (2017) discusses the role of animals in ecotourism, highlighting the issues stemming from their representation in tourism advertisements. Promotion images aim first and foremost to appeal to tourists, whilst looking authentic to local culture, thus, neglecting the consequences of the portrayal of animals as ‘passive and secondary to the tourism experience’ (Fennell, 2017, p. 186).

Planned events are both the product and expression of tradition, communal values and identity (Liutikas, 2016). Spracklen \& Lamond (2016) argue that events, especially when coupled with media, play a vital role in the spreading, normalisation and perpetuation of ideologies \& values. Therefore, similarly to media, events can have a significant effect on the way people see and treat animals.

The use of performing wild animals in circuses and marine parks has been banned in the UK and many other European countries. However, it remains a practice overseas under the guise of education (Donaldson \& Kymlicka, 2011). Sugarman (2007) states that pressure from animal rights groups threatens circuses' legacy, resulting in economic difficulties for establishments using animals. However, Sugarman fails to address why such a legacy is important, also, what is the quality of life of the animals themselves; their welfare beyond numbers of years lived. Donaldson \& Kymlicka (2011) argue that circuses, zoos and marine parks are indeed involved in education but the lessons taught are not love for, and knowledge 
of the natural world, but rather disrespect to animals' freedom and promotion of human entitlement and superiority. According to Jaynes (2008) circuses with performing animals are loved and attended by many due to their nostalgic value originating from the attendees' childhood memories. This sentiment leads Jaynes (2008, p. 5) to question, 'why do we think we have the right to force animals into these situations?' This study, therefore, explores the philosophies held by Millennials in Britain aiming specifically in relation to animal treatment in the events industry.

\section{Methodology}

As the study is exploratory, drawing on theory from different disciplines, a qualitative approach was selected. Two data collection methods were used with nine participants in a focus group and three in-depth interviews. The focus group method was selected due to the relative novelty of the topic and by encouraging a group discussion it would offer the opportunity for different opinions and arguments to emerge and develop in a dynamic conversation, closely mimicking a natural discussion (Krueger \& Casey, 2000). Building on the work of Dashper (2016) on human-horse relationships, statistical information about the British horse racing industry (see Table 1) was read to participants in the focus group, providing a starting point for the discussion and drawing on the literature, questions were developed for both the focus group and interviews (also see Table 1). The focus group helped determine general attitudes and patterns towards the use of animals in events, which were then further investigated through conducting semi-structured interviews. The interviews followed the same structure and questions as the focus group discussion - participants were first asked about their philosophies relating to nature and animals. Thereafter, the researcher directed the conversation towards the interviewee's view of animal use specifically at events. Specific insights from the focus group which were chosen for further discussion in the 
interviews were whether animals should be assigned an event stakeholder status and also what is the definition of animal welfare/fair treatment.

[Table 1 here]

Millennials were chosen as the study sample for both data collection methods, as more people aged 15-34 than any other generation, have been found to be concerned with the human impact on animals and the environment (Perlis, 2016). Adopting the sampling approach of Hill, Mobly \& McKim (2016), students, aged 18 and over, resident to southern England were identified as an opportunistic sample and were recruited by contacting student groups on social media. To achieve a heterogeneous sample, socio-demographic variables such as age, gender, country of origin, course studied and lifestyle (vegan/vegetarian/omnivore) were considered. Approximately 2\% of the UK population are vegetarian or vegan (NHS, 2015), with almost half of those being Millennials (The Vegan Society, 2017). Therefore, a small number of vegetarian/vegan participants were included in the focus group, reflecting the proportions of vegetarians/omnivores in British society.

The focus group and semi-structured in-depth interviews were undertaken in the spring of 2017, audio recorded and transcribed. All the data were combined and analysed thematically (Fox, Gouthro, Morakabati \& Brackstone, 2014) to identify patterns in responses relating to existing theory, as well as any new insights. Ethical approval from the researchers' institution was obtained prior to the data collection. This included guaranteeing the participants' anonymity throughout and therefore numbers have been assigned to each participant in the next section (P1-P9 from the focus group and P10-12 for the interviewees).

\section{Findings}

Both the focus group and interviews began by asking participants about their views concerning nature and animals. This helped to set the background and create a picture of how 
British Millennials relate to, and think, of nature. Generally, participants demonstrated a strong concern for protection of the natural world and animals. Some of the participants mentioned adopting a vegan/vegetarian lifestyle as their way to reduce their negative impact on the environment and animals. Even though all participants agreed that looking after the environment is important, they differed in their reasoning and motivation. Most believe that, 'the environment and our planet can live without us but we can't live without the planet and the animals' [P3], expressing an opinion that humans 'exist in a symbiotic relationship' [P11] with the rest of nature. Some participants demonstrated a particularly eco-centric philosophy, describing a sense of connectedness and belonging to nature, for example:

'We come from nature so it's a matter of respect as well... I feel like if you respect what was given to you, you are more likely to be a better person and live in a better world, because you are more compassionate towards what's around you.' [P6]

Participants also stated they do not agree with 'using animals for our own benefit' [P10], directly opposing anthropocentric views: ‘...we're not a supreme species. We're not the ones who own the planet, we share it, so, we should share it equally.' [P2]. These responses, therefore, express strong biocentric opinions, believing the environment and other creatures have value in themselves, regardless of their usefulness to humans. Most participants assigned moral value to animals based on their capacity for experiencing pleasure and pain (supporting Singer, 2011 and Fennell, 2012):

'Animals are creatures as well, they feel too. You like living a good life, don't you? It's basically the same.' [P12]

When discussing the reasons for animal use in planned events, novelty, 'mass entertainment' [P11] and the 'pure enjoyment of watching the animals do tricks' [P10] were stated. Participants suggested that people attend such events to satisfy their curiosity and see species 
they would not normally encounter: 'I think it's the new experience that they [people] find entertaining' [P10]. Moreover, performing animals are perceived as more relatable and 'humanised' [P10]. This belief that animals possess human characteristics or anthropomorphism is related to showing empathy towards animals (Knight \& Barnett, 2008) and was observed in this research: 'animals have so many human qualities... they have emotions.'[P1]. Knight \& Barnett's results also showed that people are more likely to empathise with animals and be concerned about animal welfare if they have had experiences with them. However, modern lifestyles, especially in Western countries, have made humans largely disconnected from the natural world. The Internet, particularly videos shared on social media, was identified by participants as their main source of information when it comes to animal welfare. This is not surprising given that online sharing has been found to be the main and preferred way of communication for Millennials (Pew Research Centre, 2010).

Anthropomorphic perceptions, resulting from animal portrayal in mass media, marketing and even wildlife documentaries may lead to people having certain unrealistic expectations from their encounters with animals which is reflected in the study by Curtin (2006). One interviewee’s account illustrates this:

'If you have ever been on a safari, for example, what do the animals do there? They are just relaxing. People don't want to see that, they want to see animals chasing other animals, doing tricks and such, so maybe that's why people prefer attending shows.' [P12]

Consistent with previous research (Galvin \& Herzog, 1992; Curtin, 2006 and Knight \& Barnett, 2009), one's personal background and experiences with animals is found to significantly affect their views. This was confirmed by a participant's narrative about their upbringing and background in relation to horse racing: 
'...then I started thinking, maybe I have been brought up with this so I'm biased and I think it's ok as we take really good care of the horses, but at the same time, why are we on top of the horse, why do we need to do that?' [P6]

Both in the focus group and interviews, the economic aspect of using animals emerged as a central issue. Whilst some participants considered capitalising on animals unfair and immoral, others saw animal-related events, such as horse racing, as providers of valuable employment. The participants expressing views in support of animal use considered a balance can be achieved between animal welfare and financial profit:

'I think it's something that's been around for such a long time in Britain, it just brings so much money in... and employs hundreds of thousands of people. So, I think we can find ways of treating them better [the horses], without it affecting [the economy] ... There are ways to make it nicer for the horses without it affecting people's jobs.' [P3]

The other group demonstrated views characterised by high moral absolutism and idealism, stating that using animals for profit is morally wrong as they 'don't belong to us' [P6]. Thus, those participants who considered animal use as essential to a healthy economy, recognised the financial benefits to compromising animal welfare. Even though the focus group began with participants expressing strong absolutist views in support of environmental protection and animal rights, as discussions progressed, more relativist statements could be observed, that is that moral values and principles are not applicable to every situation (O’Grady, 2002). For example, at the outset, all participants identified themselves as aspiring to live in harmony with the natural world, but only a small proportion then stated they had taken specific action in that direction. 
The significance of culture and tradition to animal use in events was examined by encouraging participants to compare horse racing events in Britain to bullfighting in Southern Europe. Bullfighting evoked very strong responses:

'...bullfighting is supposed to be a tradition, but we're in 2017 and animals should not be treated that way. Those bullfights are barbaric and there's not much of an excuse to treat animals like that.'[P3]

On the other hand, horse racing was subject to a more detailed conversation that produced a wider variety of views. All participants consider horse racing as more ethical with some stating there is no room for comparison with bullfighting:

‘...people have been riding horses for ages! ... not all horses are beaten, they do enjoy being trained and ridden.' [P1]

Statistical information highlighting welfare issues in the horse racing industry was presented to participants, including fatal injuries. When comparing bullfighting and horse racing, if either form of event had fatal results for the animal, participants considered horse racing more ethical and morally acceptable as the initial intention was not to hurt the animal, whereas in bullfighting, killing the bull is the end goal: 'The focus is not on hurting the horse' [P6]; 'It's not a violent thing [horse racing]' [P5]. Even though concern was expressed over the fate of horses in case of an injury resulting in inability to race, some participants stated that there are significant economic barriers to discontinuing horse racing events. Interestingly, these were not mentioned as an issue when discussing the ending of bullfighting, which was referred to as primitive and aggressive. However, culture and tradition can significantly affect one’s views and most participants had a British background and therefore, the cultural environment might be a factor influencing the opinions expressed. 
A more general negativity in response to animal treatment in events was also observed. Participants generally stated that using animals for entertainment is not justified, keeping in mind some of the training and conditioning methods involved:

'...you see these caring aspects [of the animals] that we can relate to, and then they are being whipped for entertainment ... You wouldn't do that to people, why should you do that to somebody else when they clearly care for one another...' [P5]

However, most of the participants also believed if the animals are not mistreated, using them is not immoral. When questioned how one determines if an animal is well looked after, most participants expressed opinions that can be summarised as 'being treated well and not being forced to do anything' [P7] as criteria for animal welfare. Yet, an issue prevalent in the group discussion was the very nature of using animals, which by default involves exerting some amount of control over the creature and limiting their will. This was echoed in an interview:

'you can't really tell with animals [if they are happy] ... they are being made to do tricks, whether they like it or not'. [P12]

An emerging issue is the regimented nature of events involving animals - shows and races take place at a certain time, requiring animals to perform on demand. Thus, training and conditioning is needed, much like the preparation people need in order to take part in a competition or do a certain job. However, animals are not being recognised or rewarded for their efforts, at least not in the same way people are (Singer, 1990). Some participants who had been involved in animal-related events, such as horse racing, mentioned the training and conditioning required to get the animal to respond to human command:

'We used to train horses since they were young and they would do whatever we want them to do. In the beginning, they wouldn't, but that's when you start using the whips.' [P6] 
Conditioning as a major part of training animals in sport and events was discussed by participants with disapproval:

'I guess people always say that they [the horses] enjoy it and think they're having fun but they're being whipped, it's not as extreme as bullfighting but there is cruelty involved.' [P2]

Additionally, the notion of important differences between how animals are portrayed in an event and how they are treated 'behind the scenes' was particularly common in the discussion.

Significant differences could also be observed within the group when participants were asked to reflect on events involving animals kept as pets, such as dog shows. Treatment of domesticated animals is seen as fairer and more of a symbiotic relationship beneficial for both parties, where animals provide companionship to humans in exchange for shelter and care: 'I guess people give animals life in exchange for company' [P4]. In contrast, when reflecting on the use of wild animals in shows, a popular belief among participants was that humans cannot replicate an animal's natural habitat: 'animals always look happier in the wild' [P8]. A further problem is posed by the fact people 'haven't reached that point in our development when we are able to communicate with other species' [P11]. Therefore, participants who were strongly in favour of animal rights, raised the issue of the present ambiguity around compliance:

'None of these animals can give consent... humans, it seems, we take advantage, and that's why it's such a big question, can we take advantage? We are just another species, we are not that much superior.' [P2]

Participants often explained their diminishing support and opposition to animal use in planned events, as a result of gaining more information on the ethical issues involved in such 
practices. Thus, lack of transparency and limited knowledge about animal welfare issues in the event industry were highlighted.

Whether animals are considered stakeholders is unclear, an issue which further revealed itself in the study. The stakeholder status of animals needs to be evaluated if people are to ensure their welfare. Interestingly, discussing horse racing as an animal-related event came as a surprise to some participants with one interviewee stating that they 'have never actually thought of horse racing as an animal-related event.' [P12]. Another participant's account gives further insight into the problem:

'It's really not about the horses, it's about going out, dressing up, betting, having a drink, socialising. And I feel like the horses are just there, but normally people wouldn't have any interest in horses...They're just a means to an end for making money...You see so many horses dying in these events, seen as expendable. If a horse dies, they replace it. I really don't agree with that.' [P10]

The participants considered that it is the event organisers' responsibility to provide transparency and information on animal welfare issues. However, giving more value to financial motivators rather than animal welfare is identified as a barrier for companies in acting on this responsibility and spreading awareness:

'...it's the commercial organisations' [duty to inform], because the animals are in their care - if people put pressure on them for that transparency, they may get it, but if the organisations make more money from lack of transparency, they wouldn't sacrifice their profit for the sake of the animals... That's what businesses are about today, just making more money than they did yesterday.' [P11]

\section{Discussion, Conclusion \& Recommendations}


The aim of the research was met through the exploration of a wide range of topics relating to the use of animals in events, by British Millennials. This included their opinions on the natural world, their perceptions of animal treatment within the events industry and their views on how current animal welfare issues can be resolved. The complexity of the topic became apparent as it entailed debating animal welfare and animal rights issues, which are sensitive topics, demanding in-depth discussion.

Most participants expressed opinions that can be described as biocentric. However, a wide range of nuances in people's philosophies was revealed through observing the participants' reasoning behind holding a certain view concerning animal involvement in events. People’s innate fascination with, and curiosity about nature are some of the reasons to use animals in ways, not critical to one's survival, such as planned events. Tradition, such as horse racing, and cultural festivities, such as bull fighting, are other motivators.

Some key conflicts were identified while looking at Millennial's philosophies regarding the natural world and their opinion on animal use in events. One issue is the effects of anthropomorphism. Even though anthropomorphic tendencies are related to a greater capacity for empathising with animals and opposing their exploitation, a contradiction stems from the fact these views seem to be related to engaging in activities involving animals. Some people develop greater empathy to animals and consider their use unfair, only after witnessing firsthand what is involved in having an animal at an event. However, adopting an anthropomorphic view of animals can lead to an increased demand for animal-related events, due to people's limited knowledge of animals' true nature, consisting of instincts and needs humans cannot always anticipate.

Another problem in need of attention is the lack of clear definition of animal welfare, which currently, seems to be dependent on individual interpretation. Animal rights groups and 
individuals with absolutist moral views advocate for 'animal liberation', condemning all animal use across different industries (Haynes, 2008), whereas others adopt a more pragmatic approach, claiming reducing animal suffering is enough to ensure welfare (Jasper \& Nelkin, 1992). A question that emerged from participants' responses is whether people are entitled to use animals for entertainment purposes, whilst being unsure of how well their needs are met.

Economic factors seem to be central to perpetuating animal use at events. Participants stated demand could be lessened by raising awareness of animal welfare issues and educate the public about the natural world, encouraging more ethical and sustainable practices within the event industry. However, previous research reveals cognitive dissonance associated with the use of animals in entertainment causes people to avoid upsetting information on the issue. As time progresses, people are more informed and more open to assigning rights to other species, which is evident in the progression of opinions expressed in more recent studies and literature, compared to those from a few decades ago.

'How can we care about species we have never seen?' is a question often used to challenge anti-captivity campaigners and animal rights activists (Russo, 2013). However, the adoption of an ecocentric perspective, which was found to be popular among Millennials, makes it of no importance whether one has seen a certain species of animal or not, whether one cares about that animal or not, what matters is the responsibility to allow other species to pursue life and survival on their own terms (Bekoff, 2013). Humans are neither destructive villains, nor protectors of the natural world, but rather an integral part of it (Smythe, 2014).

Limitations of the study included the relatively small number of participants and the nature of discussing sensitive morality-related topics. When talking in groups about ethics \& morals participants might feel obliged to conform to a certain 'ideal' that is considered morally 'right' or more widely spread than other views (Barbour, 2007). As the research topic touches 
on the participants' moral \& ethical values concerning the treatment of animals at events, responses gathered through the focus group discussion might not reflect views in their entirety due to concerns of how one is perceived by other participants.

A question for further research is how to bridge the gap between the ideology people express and consumer behaviour - the most prevalent views demonstrated were those related to ecocentrism and the claim that animals need to be recognised as deserving fair treatment. However, as observed by Auger \& Devinney (2007), these beliefs are not always brought into practice. As there is a recognised need for more education on animal welfare within events, challenges to raising awareness, such as cognitive dissonance and avoidance of distressing information, should be explored in further research. Additionally, a comparison could be made with participants from different cultures, such as young Spaniards who have grown up within a culture of bull fighting. The findings from this exploratory study could also be developed further through a quantitative study which measures the attitudes and may lead to a segmentation of Millennials.

In conclusion, despite event legacy having gained a central role in recent event studies (Jones, 2014), there is little theory covering the moral aspects of the human-animal relationship. Event theory places great emphasis on the importance of stakeholders (Getz, 2005; Allen et al., 2011), yet, animal use in events is rarely mentioned in event or leisure literature. Findings suggest animals are not currently considered event stakeholders, which requires further exploration. Finally, policymakers need to address the lack of a clear definition of animal welfare, which, at present seems surrounded by ambiguity and dependant on personal philosophy. 


\section{References:}

Adams, C. (2010). The war on compassion, Antennae, 14, 5-11.

Adler, M. J. (1997). Aristotle for everybody: Difficult thought made easy, New York: Touchstone Books.

Allen, J., O’Toole, W., Harris, R., \& McDonnell, I. (2011). Festival \& special event management, (5th ed.), Milton: John Wiley \& Sons Australia.

Apostol, L., Rebega, O. L., \& Miclea, M. (2012). Psychological and socio-demographic predictors of attitudes toward animals, Procedia - Social and behavioral sciences, 78, 521 525

Auger, P. \& Devinney, T.M. (2007). Do what consumers say matter? The Misalignment of Preferences with Unconstrained Ethical Intentions, Journal of Business Ethics, 76, 361-383 Barbour, R. (2007). Doing focus groups, Los Angeles: Sage Publications.

BBC. (2007). Ex-race horses should be slaughtered for meat. Retrieved from: http://www.bbc.co.uk/somerset/content/articles/2007/12/04/horseworld_feature.shtml

Bekoff, M. (2013). Animal consciousness and science matter: Anthropomorphism is not antiscience. Relations beyond anthropocentrism, 1 (1), 1-8.

Bowdin, G., Allen, J., O’Toole, W., Harris, R., \& McDonnell, I. (2011). Event management, ( $3^{\text {rd }}$ ed.), Oxford: Elsevier Butterworth-Heinemann.

Broida, J. P., Tingley, L., Kimball, R., \& Miele, J. (1993). Personality differences between pro and antivivisectionists, Society and animals, 1, 129-144

British Horse Racing Authority. (2017). About Us, British Horse Racing Authority. Retrieved from: http://www.britishhorseracing.com/bha/about-us/ 
Brown, J., Apostolova, V., Barton, C., Bolton, P., Dempsey, N., Harai, D., Hawkins, O., McGuiness, F. \& Powell, A. (2017). Millennials. Retrieved from: www.parliament.uk/commons-library

Clark, A. (2014). The Grand National: 8 Things They Don't Tell You About Horse Racing, PETA UK. Retrieved from: http://www.peta.org.uk/blog/the-grand-national-8-things-theydont-tell-you-about-horse-racing/

Cochrane, A. (2009). Do animals have an interest in liberty? Political studies 57, 660-679.

Curtin, S. (2006). Swimming with dolphins: A phenomenological exploration of tourist recollections, International journal of tourism research, 8, 301-315.

Daly, B., \& Morton, L (2009). Empathic differences in adults as a function of childhood and adult pet ownership and pet type, Anthrozoös, 22 (4), 371-382.

Dashper, K. (2016). Human-Animal relationships in equestrian sport and leisure. London: Routledge.

De Waal, F.B.M. (2001). The ape and the Sushi master: Cultural reflections of a primatologist, New York; Basic Books.

Donaldson, S., \& Kymlicka, W. (2011). Zoopolis: A political theory of animal rights, Oxford, UK: Oxford University Press.

Donaldson, T., \& Preston, L. (1995). The stakeholder theory of the corporation: concepts, evidence, and implications. Academy of management review, 20 (1), 65-91.

Fennell, D.A. (2012). Tourism and Animal Ethics, New York, NY: Routledge.

Fennell, D.A. (2017). Tourism Ethics, Bristol, UK: Channel View Publications.

Festinger, L. (1957). A theory of cognitive dissonance, Evanston, IL: Peterson 
Forsyth, D. R. (1980). Taxonomy of ethical ideologies, Journal of personality and social psychology, 39 (1), 175-184.

Fox, D., Gouthro, M.B., Morakabati, Y., \& Brackstone. J. (2014). Doing events research: from theory to practice. London: Routledge.

Galvin, S., \& Herzog, H. (1992). Ethical ideology, animal rights activism, and attitudes toward the treatment of animals, Ethics \& behaviour, 2 (3), 141-149.

Garner, R. (1993). Animals, politics and morality, Manchester, UK: Manchester University Press.

Gautam, C. K., \& Rajan, A. P. (2014). Ecocentrism in India: An incredible model of peaceful relation with nature, Universal journal of environmental research \& technology, 4 (2), 90-99.

Getz, D. (2005). Event management and event tourism, (2nd ed.), New York: Cognizant Communications Corporation

Getz, D. (2012). Event studies; Theory, research and policy for planned events, Abingdon, UK: Routledge

Hall, C. M. (1997). Hallmark tourist events: Impacts, management and planning, Chichester: John Wiley and Sons

Haynes, R. (2008). Animal welfare: Competing conceptions and their ethical implications, London, UK: Springer.

Hill, J., Mobly, M., \& McKim, B. (2016). Reaching millennials: Implications for advertisers of competitive sporting events that use animals, Journal of applied communications, 100 (2), 73-85. 
Jasper, J. M., \& Nelkin, D. (1992). The animal rights crusade: The growth of a moral protest, New York: Maxwell Macmillan International

Jaynes, M. (2008). The ethical disconnect of the circus: Humanity’s acceptance of performing elephants, Between the species, 8, 1-11.

Jones, M. (2014). Sustainable event management: A practical guide, London: Routledge Kenny, A. (2012). A new history of Western philosophy, Oxford: Oxford University Press Knight, S., \& Barnett, L. (2008). Justifying attitudes toward animal use: A qualitative study of people's views and beliefs, Anthrozoös, 21 (1), 31-42.

Krueger, R.A., Casey, M.A. (2000). Focus Groups: A Practical Guide for Applied Research, ( ${ }^{\text {rd }}$ ed.). London: Sage Publications.

Leventi-Perez, O. (2011). Disney's portrayal of nonhuman animals in animated films between 2000 and 2010 (Master’s thesis). G.A. USA: ScholarWorks @ Georgia State University, Liutikas, D. (2016). Indulgence feasts: Manifestation of religious and communal identity, In: Jepson, A., Clarke, A., (Eds.), Managing and developing communities, festivals \& events, Basingstoke UK: Palgrave McMillan UK, pp. 148-149.

Machan, T.R. (2002) Why human beings may use animals, Journal of Value Inquiry, 36 (1), 9-14.

Moss, R. (2016). Number of vegans in Britain soars in past decade, here's why. The Huffington Post UK. Retrieved from: http://www.huffingtonpost.co.uk/entry/number-of-vegans-in-uk$\underline{\text { half-million_uk_573c2557e4b0328a838b92a3 }}$ NHS (2015). Healthy eating for vegetarians and vegans [online] Retrieved from: http://www.nhs.uk/Livewell/Vegetarianhealth/Pages/Goingvegetarian.aspx 
O’Grady, P. (2002). Central problems in philosophy: Relativism, London: Routledge.

Penn, D.J. (2003). The evolutionary roots of our environmental problems: Toward a

Darwinian ecology, The quarterly review of biology, 78 (3), 275-301.

Perlis, M. (2016). Forbes survey reveals what millennials really want, Retrieved from:

https://www.forbes.com/sites/mikeperlis/2016/06/06/forbes-survey-reveals-what-millennialsreally-want/\#60d186a36755

Pew Research Centre. (2010). Millennials: A portrait of Generation Next. Confident.

Connected. Open to change Retrieved from:

http://www.pewsocialtrends.org/files/2010/10/millennials-confident-connected-open-tochange.pdf

Pifer, L., Shimizu, K., \& Pifer, R. (1994). Public attitudes towards animal research: Some international comparisons, Society and animals, 2 (2), 95-113.

Rollin, B.E. (2016). A new basis for animal ethics: Telos and common sense. Columbia: University of Missouri Press.

Russo, C. (2013). Can you worry about an animal you've never seen? The role of the zoo in education and conservation, Sci-Ed

Retrieved from: http://blogs.plos.org/scied/2013/03/11/zoo-education/

Ryder, R.D. (1970). Speciesism. Retrieved from:

http://www.criticalsocietyjournal.org.uk/Archives_files/1. Speciesism Again.pdf

Ryder, R.D. (2000). Animal revolution: Changing attitudes towards speciesism. London, UK: Bloomsbury

Ryder, R. D., \& Singer, P. (2011). Speciesism, painism and happiness: A morality for the twenty-first century, Exeter, UK: Imprint Academic 
Schultz, B. (2017). The happiness philosophers: The lives and works of the great utilitarians. Princeton, USA: Princeton University Press.

Serpell, J. (1996). In the company of animals: A study of human-animal relationships, Cambridge: Cambridge University Press.

Shapiro, P. (2006) Moral agency in other animals, Theoretical Medicine and Bioethics, 27 (4), 357-73.

Shone, A., \& Parry, B. (2010). Successful event management: A practical handbook, Andover: Cengage Learning Singer, P. (1990). Animal liberation, ( $2^{\text {nd }}$ ed.), London: Jonathan Cape Singer, P. (2011). Practical ethics, (3 ${ }^{\text {rd }}$ ed.), Cambridge: Cambridge University Press Smythe, K. (2014). Rethinking humanity and the Anthropocene: The long view of humans \& nature, Sustainability: The journal of record, 7 (3), 145-153.

Spracklen, K., \& Lamond, I.R. (2016). Critical event studies, Abingdon, Oxon: Routledge. Steiner, G. (2005). Anthropocentrism and its discontents: The moral status of animals in the history of Western philosophy, Pittsburgh, USA: University of Pittsburgh Press,

Stringer, M. D. (1999). Rethinking animism: Thoughts from the infancy of our discipline, Journal of the royal anthropological institute, 5 (4), 541-56.

Sugarman, R. (2007). The many worlds of circus. Newcastle, UK: Cambridge Scholars Publishing

The Vegan Society. (2017). Key Facts. Retrieved from: https://www.vegansociety.com/about-us/key-facts 
The Vegan Society. (2018). Key Facts, The Vegan Society. Retrieved from:

https://www.vegansociety.com/about-us/key-facts

Wilson, E.O. (1984). Biophilia London: Harvard University Press.

Xu, F., \& Fox, D. (2014). Modelling attitudes to nature, tourism and sustainable development in national parks: A survey of visitors in China and the UK. Tourism management 45, 142158. 
Table 1: British horse racing statistics and sample questions

The British horse racing industry is currently worth around $£ 3.45$ billion annually (British Horseracing Authority, 2017).

Racehorses are bred in a way that makes them genetically faster but also susceptible to health problems as a result of their unnaturally thin bones (BBC, 2007).

Two thirds of horses bred for racing never even enter the industry. Furthermore, only around 100 of the approximately 5,000 horses retiring from racing each year are taken into care. In 2010 more than 7,000 British horses were slaughtered and sold for consumption to other European countries, primarily Belgium and France, a number that has been steadily rising in the past two decades (BBC, 2007).

The Royal Society for the Prevention of Cruelty to Animals (RSPCA) states that "using whips can cause pain and suffering to the horses" but whipping the horses the entire duration of a race is a standard practice, which is banned in Norway, for example (Clark, 2014).

\begin{tabular}{|l|l|l|l|}
\hline \multicolumn{5}{|c|}{ Sample questions } \\
\hline Subtopic & $\begin{array}{l}\text { General views on the } \\
\text { relationship between } \\
\text { humans and the } \\
\text { environment }\end{array}$ & $\begin{array}{l}\text { Perceptions of the } \\
\text { treatment of animals } \\
\text { in events }\end{array}$ & $\begin{array}{l}\text { Animal use in } \\
\text { traditional events: } \\
\text { e.g. British Horse } \\
\text { Racing \& Bull } \\
\text { Fighting in Southern } \\
\text { Example question }\end{array}$ \\
& $\begin{array}{l}\text { Do you think we } \\
\text { should take care of } \\
\text { animals and the } \\
\text { environment for } \\
\text { their own sake, or } \\
\text { because of the value } \\
\text { they provide to us? }\end{array}$ & $\begin{array}{l}\text { considerations that } \\
\text { should be kept in } \\
\text { mind when using } \\
\text { animals in events? }\end{array}$ & $\begin{array}{l}\text { Are they there } \\
\text { role in horse racing? } \\
\text { because they enjoy } \\
\text { racing or because } \\
\text { they are forced to do } \\
\text { it? }\end{array}$ \\
\hline
\end{tabular}

